\title{
Erratum
}

World Journal of Microbiology \& Biotechnology (2005) 21:1187-1194 DOI $10.1007 / \mathrm{s} 11274-005-1106-6$

\section{Yeast flora during the fermentation of wines made from Vitis vinifera L. cv. Emir and Kalecik Karasi grown in Anatolia}

Canan Nurgel, Huseyin Erten, Ahmet Canbas, Turgut Cabaroglu and Serkan Selli

In the above-mentioned paper by Nurgel et al., some serious typesetting errors in Figures 3 and 5 have occurred in the final stage of the publication process. Printed below you will find the corrected figures as they should have been printed in the published paper. The correct figures will benefit the reader in better understanding the paper. Above all, it will improve the paper's scientific significance.

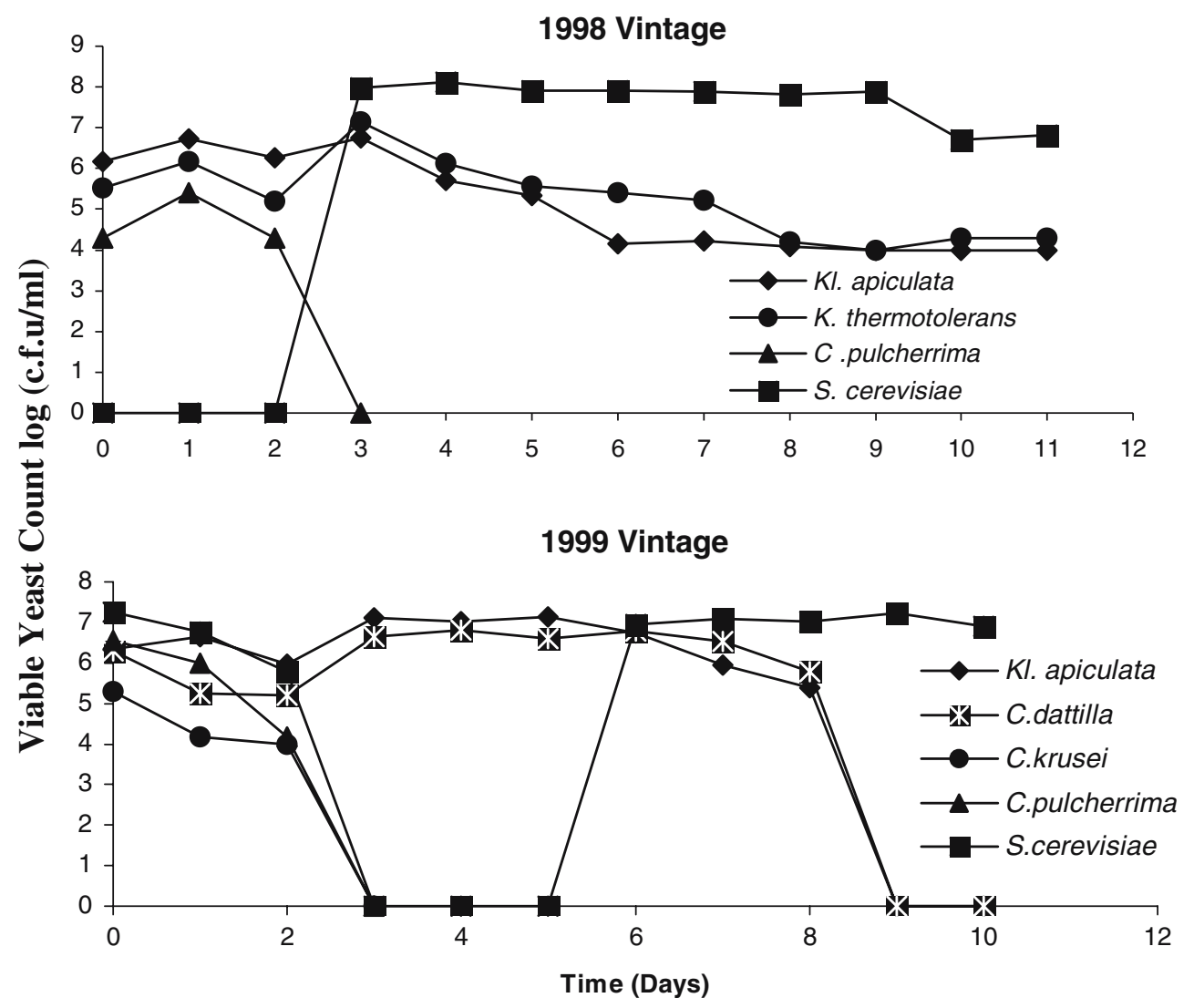

Figure 3. Evaluation of the yeast flora during the fermentation of Emir musts in 1998 and 1999 vintages. 


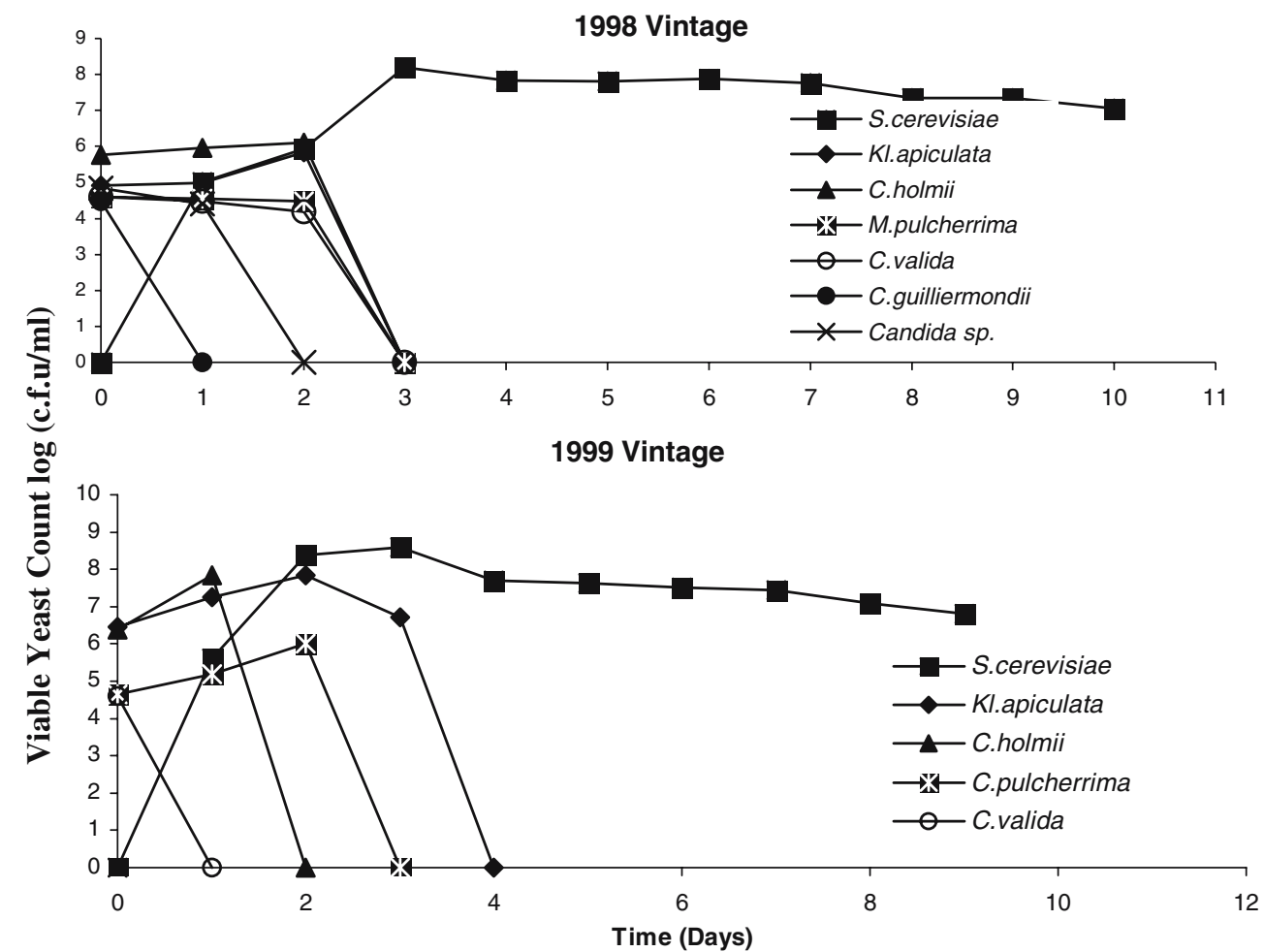

Figure 5. Evaluation of the yeast flora during the fermentation of Kalecik karasi musts in 1998 and 1999 vintages. 